\title{
Outcome of Phaco Surgeries in Patients with Pseudoexfoliation
}

\author{
Nisar Ahmed Khan*, Sobia Khan, Aisha Khan and Atiqa Khan \\ Assistant Professor/Consultant, Indus Medical College Hospital, Pakistanc
}

Submission: October 25. 2017; Published: November 20, 2017

*Corresponding author: Tando Mohammad Khan, Indus Medical College Hospital, Pakistan, Tel: Mobile: +92-300-3014168;

Email: nisargh2001@yahoo.com

Abstract

Purpose: To evaluate the results of phaco surgery in patients having cataract along pseudo exfoliation syndrome at our facility (Indus Medical College Hospital, Pakistan).

Introduction: Pseudoexfoliation (PEX) syndrome is an age-related deposition of whitish-gray pseudo exfoliation fibrillogranular amyloid like material on the anterior lens capsule, zonules. We, ciliary body, pupillary margin of the iris, corneal endothelium, anterior vitreous and trabecular meshwork. The lens frequently demonstrates a "three-ring sign" on the anterior lens capsule. Pigment loss from the iris sphincter region and its deposition on anterior chamber structures support the diagnosis. Pseudoexfoliation is a risk factor not only for open-angle glaucoma, but also for angle-closure glaucoma, lens subluxation, blood aqueous barrier impairment serious intraoperative and postoperative complication and has been correlated with an increased incidence of cataract formation. Pseudoexfoliation syndrome occurs in all areas of the world with varying frequency. There is a high prevalence in Scandinavian countries, Arabic populations and in Oman but relatively rare among African Americans, Eskimos and Canadian Arctic populations. It is more common in females than in males. Recent genetic studies in multiple populations have identified the lysyl oxidase-like 1 gene as a major contributor to the risk of developing pseudo exfoliation syndrome and pseudo exfoliation glaucoma. Some of the nongenetic factors such as ultraviolet light, autoimmunity, slow virus infection, and trauma are supposed to have an implication in the development of pseudoexfoliation. It is possible that a combination of genetic and nongenetic factors may be involved in etiopathogenesis of pseudoexfoliation and thus it may be considered as a multifactorial disorder.

Material and Methods: This study includes 23 patients who were having cataract with pseudoexfoliation syndrome and treated by phaco emulsification at Indus Medical College hospital Tando Mohammad Khan from $1^{\text {st }}$ January to 30th June 2017. Out of 23 patients $9(39.13 \%)$ were male while $14(60.86 \%)$ were females, divided into three age groups i.e. group A(41-50)yrs includes $2(8.69 \%)$ patients, group B(5160)yrs includes 5(21.73\%) patients and group C (61-70)yrs includes 16(69.56\%). 10(43.47\%) were right eyes and 13(56.52\%) eyes were left. Vision recorded using standard Snellen chart, $11(47.82 \%)$ patients were having vision $0.3,9(39.13 \%)$ were having 0.2 while remaining $3(13.04 \%)$ were having CF. Intraocular pressure measured using applanation tonometer and out of 23 patients, 10 (43.47\%) were having IOP $12 \mathrm{mmHg}, 7(30.43 \%)$ were having IOP $19 \mathrm{mmHg}$ while 6(26.08\%) were having IOP $28 \mathrm{mmHg}$. Out of these 23 patients 8(34.78\%) were using glaucoma treatment. In this study only those patients included who were having cataract up to +2 density and those having cataract density +3 or more excluded. We used mydriacil and pheniephrine eye drops to dilate the pupils. Pupillary dilatation monitor preoperatively and those having dilatation less than $5 \mathrm{~mm}$ after all efforts to dilate were excluded. We used all settings of normal phaco surgery like capsulorexhis, gentle hydrodisection and used viscoelastic to lift the nucleus away from posterior capsule and using phaco power at $50 \%$ and flow rate not exceeding more than $25 \mathrm{cc} / \mathrm{min}$ and vacuum not exceeding $200 \mathrm{mmHg}$.

With this setting we used to save posterior capsule, less stress over weak zonules and less chances of striate keratitis. Acetazolamide $250 \mathrm{mg}$ one tablet twice daily was given to all patients after surgery for one day followed by topical drops (Timolol maleate+ dorzolamide) to those who reported rise in IOP. Patients followed for up to 6 months post operatively for any further increase in IOP and dislocation of IOL.

Results: $19(82.60 \%)$ patients improved vision up to 0.7 on $1^{\text {st }}$ post operative day and gained 0.8 on $5^{\text {th }}$ post operatively day.4(17.39\%) patients developed striate keratitis with vision 0.5 on $1^{\text {st }}$ post operative day, improved to 0.7 on $5^{\text {th }}$ day and vision become 0.8 on 10 th day. Only $4(17.39 \%)$ patients developed striate keratitis post operatively managed with topical prednisolone eye drops for 7 days, 11 (including those 8 patients who were already using treatment for glaucoma) patients developed rise in IOP on first postoperative day and managed with anti glaucoma medicines i.e. acetazolamide $250 \mathrm{mg}$ orally twice daily only for one day following with topical eye drops (Timolol maleate+dorzolamide).

Conclusion: Though it is difficult to deal with patients having cataract with pseudoexfoliatin because of small pupil not dilating with mydriatics and weak zonules but with setting of phaco machine at moderate level, following the exclusion criteria, monitoring IOP pre and post operatively and using experience, good results can be achieved.

Keywords: Pseudoexfoliation syndrome; Phacoemulsification; Indus medical college hospital 


\section{Introduction}

Pseudoexfoliation (PEX) syndrome is an age-related deposition of whitish-gray pseudoexfoliation fibrillogranular amyloidlike material on the anterior lens capsule, zonules, ciliary body, pupillary margin of the iris, corneal endothelium, anterior vitreous and trabecular meshwork [1,2]. The most important and easily recognizable diagnostic sign of pseudoexfoliation is whitish-grey flaky material on the pupillary border of the iris or on the anterior surface of the lens. The lens frequently demonstrates a "three-ring sign" on the anterior lens capsule which consists of a relatively homogenous central zone and a granular cloudy peripheral zone with a clear zone in between. Pigment loss from the iris sphincter region and its deposition on anterior chamber structures support the diagnosis. Detection of these signs requires a careful clinical examination using dilated slit-lamp biomicroscopy and additionally undilated gonioscopy but frequently undiagnosed pseudoexfoliation can lead to unexpected problems in management and during surgery. The awareness of the significance of pseudoexfoliation has increased considerably in the latest decade. Pseudoexfoliation is a risk factor not only for open-angle glaucoma, but also for angle-closure glaucoma, lens subluxation, bloodaqueous barrier impairment serious intraoperative and postoperative complication and has been correlated with an increased incidence of cataract formation. Exfoliation of fibrillogranular amyloid-like material has been found in many organs such as skin, heart, lungs, liver, kidney, gall bladder, blood vessels, extraocular muscle, connective tissue in the orbit, optic nerves and meninges suggesting that the pseudoexfoliation syndrome is not only an ocular disease but also a general disorder that involves the abnormal production of extracellular matrix material $[3,4]$. Recent investigations have shown the positive link between pseudoexfoliation and transient ishemic attacks, stroke, heart disease and aneurysms of the abdominal aorta [5]. Although the exact etiology of this condition as well as the exact structure of the material is still unknown it is presumed that the production of pseudoexfoliation material is associated with abnormal metabolism of glycosaminoglycans and thus abnormalities of the basement membrane in the epithelial cells. Pseudoexfoliation syndrome occurs in all areas of the world with varying frequency. There is a high prevalence in Scandinavian countries, Arabic populations and in Oman [6,7] but relatively rare among African Americans, Eskimos and Canadian Arctic populations. It is more common in females than in males [8] and its prevalence increases steadily with age and is rarely seen before the age of 50 years and there is chances of $10 \%$ annual increase for both open-angle glaucoma and pseudoexfoliation in persons of 50 years and over in Iceland [9]. Genetic factors influencing pseudoexfoliation has been explored considerably in the latest decade [10]. Recent genetic studies in multiple populations have identified the lysyl oxidase-like 1 gene as a major contributor to the risk of developing pseudoexfoliation syndrome and pseudoexfoliation glaucoma [11]. Some of the nongenetic factors such as ultraviolet light, autoimmunity, slow virus infection, and trauma are supposed to have an implication in the development of pseudoexfoliation. It is possible that a combination of genetic and nongenetic factors may be involved in etiopathogenesis of pseudoexfoliation and thus it may be considered as a multifactorial disorder [12].

Material and Methods

Table 1: Male Female Ratio.

\begin{tabular}{|c|c|c|}
\hline Total Patients & Male & Female \\
\hline $23(100 \%)$ & $9(39.13 \%)$ & $14(60.86 \%)$ \\
\hline
\end{tabular}

Table 2: Age at Presentation.

\begin{tabular}{|c|c|c|}
\hline Total Patients & Male & Female \\
\hline $23(100 \%)$ & $9(39.13 \%)$ & $14(60.86 \%)$ \\
\hline
\end{tabular}

Table 3: Laterality.

\begin{tabular}{|c|c|c|c|}
\hline Total Patients & $\begin{array}{c}\text { Group A } \\
(\mathbf{4 1 - 5 0 ) y r s}\end{array}$ & $\begin{array}{c}\text { Group B } \\
(\mathbf{5 1 - 6 0 ) y r s}\end{array}$ & $\begin{array}{c}\text { Group C (61- } \\
\mathbf{7 0}) \mathbf{y r s}\end{array}$ \\
\hline $23(100 \%)$ & $2(8.69 \%)$ & $5(21.73 \%)$ & $16(69.56 \%)$ \\
\hline
\end{tabular}

Table 4: Visual Acuity at Presentation.

\begin{tabular}{|c|c|c|}
\hline Total Patients & Right Eye & Left Eye \\
\hline $23(100 \%)$ & $10(43.47 \%)$ & $13(56.52 \%)$ \\
\hline
\end{tabular}

Table 5: IOP at Presentation.

\begin{tabular}{|c|c|c|c|}
\hline Total Patients & $\mathbf{0 . 3}$ & $\mathbf{0 . 2}$ & CF at 1Meter \\
\hline $23(100 \%)$ & $11(47.82 \%)$ & $9(39.13 \%)$ & $3(13.04 \%)$ \\
\hline
\end{tabular}
Table 6: Patients on antiglaucoma medication at Presentation.
\begin{tabular}{|c|c|c|c|}
\hline Total Patients & $\mathbf{1 2} \mathbf{~} \mathbf{m H g}$ & $\mathbf{1 9} \mathbf{~} \mathbf{m H g}$ & $\mathbf{2 8} \mathbf{~ m m H g}$ \\
\hline $23(100 \%)$ & $10(43.47 \%)$ & $7(30.43 \%)$ & $6(26.08 \%)$ \\
\hline
\end{tabular}

This study includes 23 patients who were having cataract with pseudo exfoliation and treated by phaco emulsification at Indus Medical College hospital Tando Mohammad Khan from $1^{\text {st }}$ January to 30th June 2017. Out of 23 patients $9(39.13 \%)$ were male while $14(60.86 \%)$ were females (Table 1$)$, divided into three age groups i.e. group A(41-50)yrs includes 2(8.69\%) patients, group $\mathrm{B}(51-60)$ yrs includes $5(21.73 \%)$ patients and group C (61-70)yrs includes 16(69.56\%) (Table 2). 10(43.47\%) were right eyes and $13(56.52 \%)$ eyes were left (Table 3). Vision recorded using standard Snellen chart, 11(47.82\%) patients were having vision $0.3,9(39.13 \%)$ were having 0.2 while remaining 3(13.04\%) were having CF (Table 4). Intraocular pressure measured using applanation tonometer and out of 23 patients, 10 (43.47\%) were having IOP $12 \mathrm{mmHg}$ 7(30.43\%) were having IOP $19 \mathrm{mmHg}$ while 6(26.08\%) were having IOP 28 mmHg (Table 5). Out of these 23 patients $8(34.78 \%$ ) were using glaucoma treatment (Table 6).

In this study only those patients included who were having cataract up to +2 density and those having cataract density +3 or more excluded. We used mydriacil and pheniephrine eye drops to dilate the pupils. Pupillary dilatation monitor preoperatively and those having dilatation less than $5 \mathrm{~mm}$ after all efforts to dilate were excluded. Though it is difficult to deal with patients 
having cataract with pseudoexfoliatin because of small pupil not dilating with mydriatics and weak zonules. We done phaco emulsification to all these 23 patients using Zeiss microscope and white star signature (AMO) phaco machine. Preoperatively every patient was given acetazolamide $250 \mathrm{mg}$ only one tablet one hour prior surgery and IOP measured before surgery. Local anesthesia given using retro bulbar and facial (Vonlint) with $2 \%$ lidocaine (xylocain) injections. After asceptic techniques, drapping and using 2 drops of $10 \%$ povidine solution instilled into eye, after 1 minute copious irrigation done, incision started with $2.8 \mathrm{~mm}$ phaco knife, capsulorexhis done with 27 gauge bent needle, gentle hydrodissection and in some hydrodileanation using small caliber irrigation cannula, copious use of $2 \%$ methylcellulose to save endothelium as well as to maintain anterior chamber. All 4 steps of phaco followed and finally injectable intraocular lens implanted. Wound closed with stromal hydration. Every operation finished with sub conjunctival injection of Dexamethasone $2 \mathrm{mg}$ plus gentamicin $20 \mathrm{mg}$, and eye kept patched for 24 hours. We did not use capsular tension ring in any of these patients during surgery.

We used all settings of normal phaco surgery like capsulorexhis, gentle hydrodisection and used viscoelastic to lift the nucleus away from posterior capsule and using phaco power at $50 \%$ and flow rate not exceeding more than $25 \mathrm{cc} /$ min and vacuum not exceeding $200 \mathrm{mmHg}$. With this setting we used to save posterior capsule, less stress over weak zonules and less chances of striate keratitis. Acetazolamide $250 \mathrm{mg}$ one tablet twice daily was given to all patients after surgery for one day followed by topical drops (Timolol maleate+ dorzolamide) to those who reported rise in IOP. Patients followed for up to 6 months post operatively for any further increase in IOP and dislocation of IOL.

\section{Results}

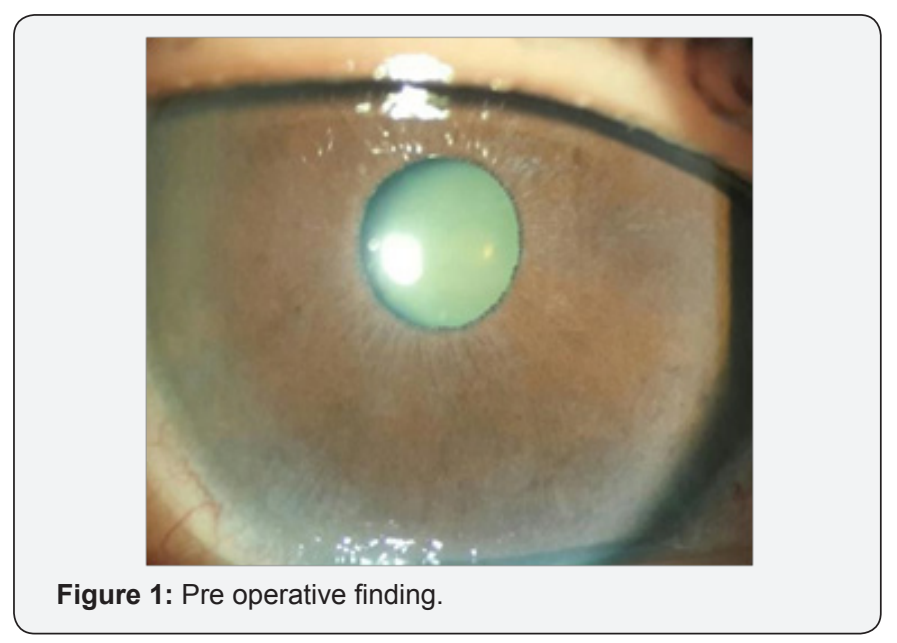

All patients were treated by phaco emulsification using normal settings of phaco surgery like capsulorexhis, gentle hydrodisection and used viscoelastic to lift the nucleus away from posterior capsule and using phaco power at $50 \%$ and flow rate not exceeding more than $22 \mathrm{cc} / \mathrm{min}$ and vacuum not exceeding $200 \mathrm{mmHg}$. With this setting we used to save posterior capsule, less stress over weak zonules. We and less chances of striate keratitis. We used injectable intra ocular lens (Hoya, Japan) implantation to all these patients. Figure $1 \& 2$ shows pre and post operative finding. Patients followed for up to 6 months post operatively for any increase in IOP and dislocation of IOL (intraocular lens).

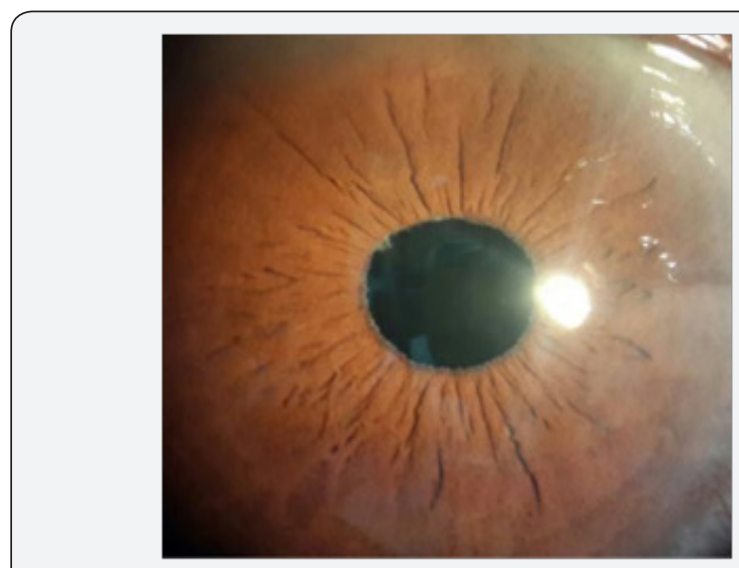

Figure 2: Post operative finding.

Table 7: Visual outcome.

\begin{tabular}{|c|c|c|c|}
\hline \multirow{2}{*}{$\begin{array}{c}\text { No of } \\
\text { patients }\end{array}$} & \multicolumn{3}{|c|}{ Visual acuity } \\
\cline { 2 - 4 } & $\begin{array}{c}\mathbf{1}^{\text {st }} \text { post } \\
\text { operative day }\end{array}$ & $\begin{array}{c}\mathbf{5}^{\text {th }} \text { post } \\
\text { operative day }\end{array}$ & $\begin{array}{c}\mathbf{1 0}^{\text {th }} \text { post } \\
\text { operative day }\end{array}$ \\
\hline $19(82.60 \%)$ & 0.7 & 0.8 & 0.8 \\
\hline $4(17.39 \%)$ & 0.5 & 0.7 & 0.8 \\
\hline
\end{tabular}

$19(82.60 \%)$ patients improved vision up to 0.7 on 1 st post operative day and gained 0.8 on 5 th post operatively day. $4(17.39 \%)$ patients developed striate keratitis with vision 0.5 on 1st post operative day, improved to 0.7 on 5 th day and vision become 0.8 on 10 th day (Table 7$)$. Only $4(17.39 \%$ ) patients developed striate keratitis post operatively managed with topical prednisolone eye drops for 7 days, 11(including those 8 patients who were already using treatment for glaucoma) patients developed rise in IOP on first postoperative day and managed with anti glaucoma medicines i.e. acetazolamide $250 \mathrm{mg}$ orally twice daily only for one day following with topical eye drops (Timolol maleate + dorzolamide).

\section{Discussion}

Though it is difficult to deal with patients having cataract with pseudoexfoliatin because of small pupil not dilating with mydriatics and weak zonules. We done phaco emulsification to all these 23 patients using normal settings of phaco surgery like capsulorexhis, gentle hydrodisection and used viscoelastic to lift the nucleus away from posterior capsule and using phaco power at $50 \%$ and flow rate not exceeding more than $22 \mathrm{cc} / \mathrm{min}$ and vacuum kept not more than $200 \mathrm{mmHg}$. With this setting we used to save posterior capsule, less stress over weak zonules and less chances of striate keratitis. It is mandatory to do frequent eye 
examination for these post operative cases for early detection of an increase of IOP, inflammation and IOL dislocation. Kaštelan S et al. [13] \& Drolsum L et al. [14] used to administered acetazolamide immediately after surgery and using topical glaucoma mediators in the postoperative period can effectively control the rise of IOP. We adopted the same strategy to control post operative rise in IOP. Küchle M et al. [15], Jehan FS [16] in their studies have shown that patients with pseudoexfoliation syndrome have higher rates of complications during and after cataract surgery compared to patients without this disorder but in our setting only 4 patients developed striate keratitis, there is no capsular rupture or lens dislocation observed in our study for up to six months follow up. Ritch R et al. [17] \& Naumann GO et al. [1] found that heparin surface modified posterior chamber IOLs associated with fewer postoperative fibrinoid reactions, less frequent pigment and cellular deposits on the lenses and lower incidence of the posterior synechiae formation than other forms of IOLs furthermore, flexible silicone IOLs should not to be used to prevent capsular contraction syndrome. In our study we used Hoya(Japan) and got no complication like these. With regards to the phaco technique, it is recommended that each surgeon applies his technique of preference. For denser nucleus horizontal chop is preferred technique whilst for softer nucleus anterior phaco technique. To avoid zonular stress we adjust machine settings in the medium range (vacuum not exceeding $200 \mathrm{mmHg}$, aspiration flow rate $20-25 \mathrm{cc} / \mathrm{min}$, phaco power not more than $50 \%$ and continuous). Cortex removal is a critical step and care should be taken not to engage the margins of anterior capsule to avoid stress over zonules.

Kuchle $\mathrm{M}$ et al. [18] having same opinion in their study regarding the frequency of intraoperative and postoperative complications such as zonular dialysis, capsular rupture, vitreous loss and IOL decentration that can be reduced with careful attention and precise surgical technique. Küchle M et al. [15], Scorolli L et al. [19], Georgopoulos GT et al. [20] Drolsum L et al. [21] observed a lower complication rate during PHACO than extracapsular extraction in eyes with pseudoexfoliation, same as our results.

Busic M et al. [22], Malyugin B et al. [23] used pupil expanding device, Malyugin ring that exerts less iris trauma and adequately dilates the pupil and simultaneously prevents iris sphincter damage. It is easy to insert and remove, sufficiently expands the pupil, protects the iris sphincter during surgery and allows the pupil to return to its normal shape, size and function after the operation but we did not use any CTR or pupil expanding device and the results were excellent at our facility.

\section{Conclusion}

Though it is difficult to deal with patients having cataract with pseudoexfoliatin because of small pupil not dilating with mydriatics and weak zonules but with setting of phaco machine at moderate level, following the exclusion criteria, monitoring
IOP pre and post operatively and using experience, good results can be achieved.

\section{Acknowledgement}

I am thankful to Aisha Khan (4th year MBBS) Atiqa Khan (final year BDS) students at Isra University Hospital Pakistan and Sobia Khan (2nd year MBBS) student at Indus medical College hospital Pakistan for their help in compiling data. Special thanks to my assistant Moin Shaikh for his continuous help.

\section{References}

1. Naumann GO, Schlötzer-Schrehardt U, Küchle M (1998) Pseudoexfoliation syndrome for the comprehensive ophthalmologist. Intraocular and systemic manifestations. Ophthalmology 105(6): 951968.

2. Schlötzer-Schrehardt U, Naumann GO (2006) Ocular and systemic pseudoexfoliation syndrome. Am J Ophthalmol 141(5): 921-937.

3. Schlötzer-Schrehardt UM, Koca MR, Naumann GO, Volkholz H (1992) Pseudoexfoliation syndrome. Ocular manifestation of a systemic disorder? Arch Ophthalmol 110(12): 1752-1756.

4. Streeten BW, Li ZY, Wallace RN, Eagle RC Jr, Keshgegian AA (1992) Pseudoexfoliative fibrillopathy in visceral organs of a patient with pseudoexfoliation syndrome. Arch Ophthalmol 110(12): 1757-1762.

5. Shrum KR, Hattenhauer MG, Hodge D (2000) Cardiovascular and cerebrovascular mortality associated with ocular pseudoexfoliation. Am J Ophthalmol 129(1): 83-86.

6. Summanen P, Tönjum AM (1988) Exfoliation syndrome among Saudis. Acta Ophthalmol Suppl 184: 107-111.

7. Bialasiewicz AA, Wali U, Shenoy R, Al-Saeidi R (2005) Patients with secondary open- angle glaucoma in pseudoexfoliation (PEX) syndrome among a population with high prevalence of PEX. Clinical findings and morphological and surgical characteristics. Ophthalmologe 102(11): 1064-1068.

8. Kozart DM, Yanoff M (1982) Intraocular pressure status in 100 consecutive patients with exfoliation syndrome. Ophthalmology 89(3): 214-218.

9. Jonasson F, Damji KF, Arnarsson A, Sverrisson T, Wang L, et al. (2003) Prevalence of open-angle glaucoma in Iceland: Reykjavik Eye Study. Eye (Lond) 17(6): 747-753.

10. Zenkel M, Pöschl E, von der Mark K, Hofmann-Rummelt C, Naumann GO, et al. (2005) Differential gene expression in pseudoexfoliation syndrome. Invest Ophthalmol Vis Sci 46(10): 3742-3752.

11. Challa P (2009) Genetics of pseudoexfoliation syndrome. Curr Opin Ophthalmol 20(2): 88-91.

12. Damji KF, Bains HS, Stefansson E, Loftsdottir M, Sverrisson T, et al. (1998) Is pseudoexfoliation syndrome inherited? A review of genetic and nongenetic factors and a new observation. Ophthalmic Genet 19(4): 175-185.

13. Kaštelan S, Bušic M (2003) Pseudoexfoliation syndrome and cataract surgery. Ophthalmologia Croatica 11: 37-40.

14. Drolsum L, Ringvoid A, Nicolaissen B (2007) Cataract and glaucoma surgery in pseudoexfoliation syndrome: a review. Acta Ophthalmol Scand 85: 810-821.

15. Küchle M, Viestenz A, Martus P, Händel A, Jünemann A, et al. (2000) Anterior chamber depth and complications during cataract surgery in eyes with pseudoexfoliation syndrome. Am J Ophthalmol 129(3): 281285. 
16. Jehan FS, Mamalis N, Crandall AS (2001) Spontaneous late dislocation of intraocular lens within the capsular bag in pseudoexfoliation patients. Ophthalmology 108(10): 1727-1731.

17. Ritch R, Schlötzer-Schrehardt U (2001) Exfoliation syndrome. Surv Ophthalmol 45(4): 265-315.

18. Kuchle M, Amberg A, Martus P, Nguyen NX, Naumann GO (1997) Pseudoexfoliation syndrome and secondary cataract. Br J Ophthalmol 81(10): 862-866.

19. Scorolli L, Scorolli L, Campos EC, Bassein L, Meduri RA (1998) Pseudoexfoliation syndrome: a cohort study on intraoperative complications in cataract surgery. Ophthalmologica 212(4): 278-280.
20. Georgopoulos GT, Chailkiadakis J, Livir-Rallatos G, Theodossiadis PG, Theodossiadis GP (2000) Combined clear cornea phacoemulsification and trabecukar aspiration in the treatment of pseudoexfoliation glaucoma associated with cataract. Grafes Arch Clin Exp Ophthalmol 238(10): 816-821.

21. Drolsum L, Haaskjoid E, Sandvig K (1998) Phacoemulsification in eyes with pseudoexfoliation. J Cataract Refarct Surg 24(6): 787-792.

22. Busic M, Kastelan S (2005) Pseudoexfoliation syndrome and cataract surgery by phacoemulsification. Coll Antropol 1: 163-166.

23. Malyugin B (2007) Small pupil phaco surgery: a new technique. Ann Ophthalmol(Skokie) 39(3): 185-193. 